\title{
Bioenergetic dysfunction and inflammation in Alzheimer's disease: a possible connection
}

\author{
Heather M. Wilkins ${ }^{1,2}$, Steven M. Carl ${ }^{2}$, Alison C. S. Greenlief ${ }^{2}$, Barry W. Festoff ${ }^{1,3,4,5}$ and \\ Russell H. Swerdlow ${ }^{1,2,4,6 *}$
}

1 Department of Neurology, University of Kansas Medical Center, Kansas City, KS, USA

${ }^{2}$ University of Kansas Alzheimer's Disease Center, University of Kansas Medical Center, Kansas City, KS, USA

${ }^{3}$ Department of Pharmacology, University of Kansas Medical Center, Kansas City, KS, USA

${ }^{4}$ Department of Molecular and Integrative Physiology, University of Kansas Medical Center, Kansas City, KS, USA

${ }^{5}$ pHLOGISTIX Neurodiagnostics, Lenexa, KS, USA

${ }^{6}$ Department of Biochemistry and Molecular Biology, University of Kansas Medical Center, Kansas City, KS, USA

\section{Edited by:}

Elena Galea, Universitat Autònoma de Barcelona, Spain

Reviewed by:

Changiz Geula, Northwestern

University, USA

Gloria Patricia Cardona Gomez,

University of Antioquia, Colombia

\section{*Correspondence:}

Russell H. Swerdlow, University of

Kansas School of Medicine, MS 2012,

Landon Center on Aging, 3901

Rainbow Blvd, Kansas City, KS 66160,

USA

e-mail: rswerdlow@kumc.edu
Inflammation is observed in Alzheimer's disease (AD) subject brains. Inflammation-relevant genes are increasingly implicated in AD genetic studies, and inflammatory cytokines to some extent even function as peripheral biomarkers. What underlies AD inflammation is unclear, but no "foreign" agent has been implicated. This suggests that internally produced damage-associated molecular pattern (DAMPs) molecules may drive inflammation in AD. A more complete characterization and understanding of AD-relevant DAMPs could advance our understanding of $A D$ and suggest novel therapeutic strategies. In this review, we consider the possibility that mitochondria, intracellular organelles that resemble bacteria in many ways, trigger and maintain chronic inflammation in AD subjects. Data supporting the possible nexus between $\mathrm{AD}$-associated bioenergetic dysfunction are discussed.

Keywords: inflammation, bioenergetics, DAMP, mitochondria, Alzheimer's disease

\section{INFLAMMATION IN AD}

The role of inflammation in Alzheimer's disease (AD) was first observed approximately four decades ago (Ishii and Haga, 1976). Beyond the identification of elevated immune cells and cytokines in $\mathrm{AD}$ brain, many lines of evidence implicate inflammation as a pathological AD hallmark. For instance, the use of non-steroidal anti-inflammatory drugs (NSAIDs) associates with decreased AD risk (Breitner et al., 1994; Rich et al., 1995). Additionally, a number of genes recently associated with AD risk through genome wide association studies (GWAS) play a role in inflammation or inflammatory signaling.

Abbreviations: ABCA7, ATP-binding cassette, sub-family A (ABC1), member 7; $\mathrm{AD}$, Alzheimer's disease; AGE, advanced glycation endproduct; $\mathrm{AKT}$, protein kinase B; ATP, adenosine triphosphate; CCR3, C-C motif receptor 3; CCR5, C-C motif receptor 5; CD33, cluster of differentiation 33; CLU, clusterin; CNS, central nervous system; COX2, cyclooxygenase 2; COX-IV, cytochrome oxidase; $\mathrm{CpG}$, cytosine followed by guanine cite of methylation in DNA; CR1, complement receptor 1; $\mathrm{CRP}$, C reactive protein; CSF, cerebral spinal fluid; CXCR2, chemokine C-X-C motif receptor 2; DAMP, damage-associated molecular pattern; DeMP, oxidantinitiated degraded mitochondrial polynucleotides; ECAR, extracellular acidification rate; EPHA1, epherin receptor A1; ERK, extracellular signal-regulated kinase; ETC, electron transport chain; FDG-PET, fluorodeoxyglucose (18F) positron emission tomography; fMLP, formyl-methionine, leucine, phenylalanine; FPR, formyl peptide receptor; GPCR, G protein-coupled receptor; GWAS, genome wide association study; HMGB1, high mobility group box 1; ICAM, intracellular adhesion molecule; IFN $\alpha$, interferon alpha; IL-1, interleukin 1; IL-6, interleukin 6; IL-8, interleukin 8; IL10, interleukin 10; IL-12, interleukin 12; INF $\gamma$, interferon gamma; iNOS, inducible nitric oxide synthase; INPPD5, inositol polyphosphate-5-phosphatase; JNK, cJun N-terminal kinase; LPS, lipopolysaccharide; MAC, membrane attack complex; MAPK, mitogen activated protein kinase; MCI, mild cognitive impairment;
While an immediate response to an invasive pathogen is beneficial, a sustained inflammatory reaction will lead to tissue damage and functional decline. The cells responsible for an immune response in the brain are microglia and astrocytes (Akiyama et al., 2000a). In 1994, Akiyama et al. reviewed the contribution of microglial activation to neuroinflammation in $\mathrm{AD}$. The $\beta$-amyloid plaques of deceased $\mathrm{AD}$ patients were found to contain significant amounts of activated microglia (Akiyama, 1994). Microglia from $\mathrm{AD}$ patients express major histocompatibility complex class II (MHCII) molecules, cyclooxygenase 2 (COX2), and cytokines/chemokines such as monocyte chemotactic protein

MCP-1, monocyte chemotactic protein 1; MCP-3, monocyte chemotactic protein 3; MEFC2, myocyte-specific enhancer factor 2C; MHCII, major histocompatibility class II; MIP- $1 \alpha$, macrophage inflammatory protein 1 alpha; MIP-2 $\alpha$, macrophage inflammatory protein 2 alpha; MMP-8, matrix metalloproteinase-8; MPTP, methyl-4-phenyl-1,2,3,6-tetrahydropyridine; mtDNA, mitochondrial DNA; NFKB, nuclear factor kappa-light-chain-enhancer of activated B cells; NLRP3, NOD-like receptor family, pyrin domain containing 3; NO, nitric oxide; NSAID, non-steroidal anti-inflammatory drug; OCR, oxygen consumption rate; PAI-1, plasminogen activator inhibitor-1; PAMP, pathogen-associate molecular pattern; PI3K, phosphatidylinositol-4,5-bisphosphate 3-kinase; PRR, pattern recognition receptor; PTK2B, protein tyrosine kinase 2 beta; RAGE, receptor for advanced glycation endproducts; RANTES, regulated on activation, normal T cell expressed and secreted RIG-1, retinoic acid inducible gene-1; RNS, reactive nitrogen species; ROS, reactive oxygen species; SIRS, systemic inflammatory response syndrome; SNP, single nucleotide polymorphism; TCA, citric acid cycle; TFAM, mitochondrial transcription factor A; TGF $\beta$, transforming growth factor beta; TLR, toll like receptor; TNBS, 2,4,6-trinitrobenzenesulfonic acid; TNF $\alpha$, tumor necrosis factor alpha; tPA, tissue plasminogen activator; TREM2, triggering receptor expresses on myeloid cells 2; VCAM, vascular cell adhesion molecule. 
1 (MCP-1), TNF $\alpha$, and IL-1 $\beta$ (Akiyama et al., 2000b). Postmortem AD brain analysis depicted elevated IL- $1 \alpha$, CXCR2 (IL-8 receptor $\beta$ ), CCR3 (C-C chemokine receptor type 3, CD193), CCR5 (C$\mathrm{C}$ chemokine receptor type 5, CD195), and transforming growth factor $\beta$ (TGF $\beta$ ) (Cartier et al., 2005). The activity of numerous immune system pathways are increased in $\mathrm{AD}$, including complement, membrane attack complexes (MAC), and cytokines such as; IL-1, IL-6, and TNF $\alpha$. These have been extensively reviewed elsewhere (Akiyama et al., 2000a).

Beyond direct measurement of inflammatory pathway mediators and effectors, brain inflammation can be measured in living subjects through the use of PK11195. This molecule is an isoquinoline carboxamide, which binds to the peripheral benzodiazepine receptor. Within the context of the central nervous system (CNS), PK11195 binds to glial cells, such as astrocytes and microglia. Compared to control subjects, $\mathrm{AD}$ patients have elevated binding of radiolabeled PK11195. Furthermore, a correlation between brain PK11195 labeling and cognitive deterioration is prominent in AD patients (Cagnin et al., 2001; Versijpt et al., 2003).

Recent genetic association studies have revealed genes that regulate or encode inflammatory proteins associated with AD risk. These are reviewed here and in Table $\mathbf{1}$. Two genes, which specifically regulate phagocytosis influence $\mathrm{AD}$ risk. $\mathrm{R} 47 \mathrm{H}$, a novel genetic variant of triggering receptor expressed on myeloid cells 2 (TREM2), impedes the normal function of this protein (Jonsson et al., 2013). TREM2 functions to suppress cytokine production and modulates microglial phenotype into a more phagocytic role. Mutations of TREM2 reduce microglial phagocytosis by preventing its maturation and transport to the cell membrane (Kleinberger et al., 2014). Cerebral spinal fluid (CSF) levels of soluble TREM2 are reduced in AD subjects, although no significant difference is observed in plasma (Kleinberger et al., 2014). A potential role for TREM2 in $\mathrm{AD}$ has been reviewed extensively elsewhere (Jiang et al., 2013). The other gene, adenosine triphosphate (ATP)binding cassette subtype family A member 7 (ABCA7), encodes a protein, which regulates macrophage phagocytosis and the transport of molecules across the plasma membrane (Hollingworth et al., 2011).

Single nucleotide polymorphisms of genes encoding components of the complement cascade and MHC molecules enhance $\mathrm{AD}$ risk. The complement system aids in antibody presentation and phagocytosis processes relevant to the clearance of antigens or inflammatory stimuli (Hazrati et al., 2012). Complement component receptor 1 (CR1) and clusterin (CLU) associate with increased $\mathrm{AD}$ risk (Lambert et al., 2009). CR1 is a type one transmembrane protein involved in activation of glial cells. CR1 activates complement signaling and phagocytosis (Lambert et al., 2009). CLU is a complement inhibitor, with other functions that relate to apoptosis and modulation of NFkB signaling (Harold et al., 2009; Lambert et al., 2009). MHC molecules present antigens for immune responses, of which one single nucleotide polymorphisms (SNP) found in the HLA-DRB5/DRB1 gene is a risk factor for $\mathrm{AD}$.

Genes encoding proteins, which regulate immune cell function (EPHA1, INPPD5, and CD33) associate with AD risk. Ephrin type A receptor 1 (EPHA1) is highly expressed in early stages of inflammation and may play a role in the redistribution of epithelial cell barriers (Ivanov and Romanovsky, 2006). EPHA1 also regulates cell motility and morphology. Phosphatidylinositol3,4,5-trisphosphate 5-phosphatase 1 (INPPD5) is expressed in hematopoietic cells (which give rise to immune cells such as macrophages and T cells). INPPD5 has been implicated in the regulation of microglial cell function. CD33 is a transmembrane receptor, which belongs to the Siglec family (sialic acid binding immunoglobulin-type lectins, or carbohydrate binding proteins), which bind and recognize sialic acid. Sialic acid is a general term for derivatives of neuraminic acid or the keto-deoxynonulosonic acid of nine-carbon sugars found on many proteins and lipids. Sialic acids function to mediate selective cell-to-cell interactions (Crocker and Varki, 2001). In particular, CD33 is expressed

Table 1 | Genetic variants associated with AD risk and inflammatory pathways.

\begin{tabular}{llcl}
\hline Gene symbol & Function & Variation associated with AD & Reference \\
\hline TREM2 & Phagocytosis/control of microglial phenotype & rs75932628 (R47H) & $\begin{array}{l}\text { (Jiang et al., 2013; Jonsson et al., 2013; } \\
\text { Kleinberger et al., 2014) }\end{array}$ \\
CR1 & Complement signaling phagocytosis & rs6656401 & (Lambert et al., 2009; Hazrati et al., 2012) \\
EPHA1 & Epithelial cell barriers & rs11767557 & (Hollingworth et al., 2011) \\
& Cell motility and morphology & rs11771145 & (Lambert et al., 2013) \\
HLA-DRB5/DRB1 & MHC signaling & rs9271172 & (Lambert et al., 2013) \\
INPPD5 & Microglial cell function & rs35349669 & (Lambert et al., 2013) \\
MEFC2 & Effector of MAPK signaling/activates c-Jun & rs190982 & (Lambert et al., 2013) \\
PTK2B & Activates MAPK signaling & rs28834970 & (Hollingworth et al., 2011) \\
CD33 & Cell-cell interactions & rs3865444 & (Hollingworth et al., 2011) \\
& Immune cell function endocytosis & rs3826656 & (Harold et al., 2009; Lambert et al., 2009)
\end{tabular}


on myeloid cells where it promotes cell-to-cell interactions and regulates inflammatory function (Hollingworth et al., 2011).

Single nucleotide polymorphisms which alter inflammatory signaling pathways increase AD risk. Monocyte specific enhancing factor 2 (MEFC2) is a transcription factor. Protein tyrosine kinase $2 \beta$ (PTK2B), is a cytoplasmic tyrosine kinase. PTK2B activates p38 MAPK signaling, which ultimately activates inflammatory pathways, while MEFC2 is a downstream effector of p38 MAPK signaling (Han et al., 1997). C-Jun activation is mediated by MEFC2, and is thus highly associated with inflammatory cascades. Notably, c-Jun is up-regulated in hippocampi from $\mathrm{AD}$ subject postmortem brain tissue (Marcus et al., 1998). Genetic susceptibility loci and polymorphisms for each of these genes have been associated with $\mathrm{AD}$ risk (McGeer and McGeer, 2001; Ivanov and Romanovsky, 2006; Hollingworth et al., 2011; Hazrati et al., 2012; Lambert et al., 2013).

To some extent peripheral inflammatory markers may reflect one's likelihood of developing dementia. Some conflict exists regarding IL- 6 and $C$ reactive protein (CRP) correlation with disease risk. While IL-6 and CRP levels positively correlate with dementia risk, other studies found no association with AD risk (Engelhart et al., 2004; Sundelof et al., 2009). A relationship between IL-1, TNF $\alpha$, and the development of AD has been observed (Tan et al., 2007). In one eloquent longitudinal study, midlife IL-6 elevation served as a predictor of cognitive decline (Singh-Manoux et al., 2014). Thus, not only are plasma inflammatory markers promising early biomarkers, inflammation-related changes appear to precede the overt clinical dementia phenotype.

Strong evidence linking neuroinflammation and AD progression has propagated a new hypothesis termed "cycle of selfperpetuating inflammatory neurotoxicity." This hypothesis suggests that after the initial inflammatory stimuli activates microglia, the inflammatory tissue damage induces neuronal cell death that ultimately propagates to other brain areas (Block et al., 2007). Chronic inflammation is proposed to be a result of two possible factors; a lack of clearance of the inflammatory stimulus, or a failure to resolve the inflammatory process (Glass et al., 2010). It is further hypothesized that a disruption of homeostasis between cell death and phagocytosis is a prominent factor contributing to pathological inflammation in diseases (Zitvogel et al., 2010).

The factor or factors that initiate inflammation in $\mathrm{AD}$ remain elusive. One factor that may substantially contribute to chronic inflammation is bioenergetic dysfunction, which may arise at the level of the mitochondria. We review the evidence for bioenergetic dysfunction in $\mathrm{AD}$ below.

\section{BIOENERGETIC DYSFUNCTION IN AD}

The term "bioenergetics" refers to cell energy metabolism. Bioenergetic flux is observed through the overall flow of individual biochemical pathways (Swerdlow, 2014). Three major bioenergetic pathways facilitate carbohydrate-based energy production - glycolysis, the Krebs cycle (or the citric acid cycle; TCA), and oxidative phosphorylation. These pathways are commonly examined when determining bioenergetic function. Glycolysis is an anaerobic process that takes place in the cytoplasm and results in low energy yield. The aerobic TCA cycle and oxidative phosphorylation phases, which occur at the matrix and inner membrane of mitochondria, respectively, can generate larger amounts of energy. Bioenergetic flux is a multidirectional measurement, with forward movement referring to the energy producing, catabolic direction (i.e., glycolysis $\rightarrow$ TCA $\rightarrow$ oxidative phosphorylation). The brain is particularly vulnerable to reductions in aerobic bioenergetic flux because of its high energy demand and relatively elevated mitochondrial content. Declining bioenergetic fluxes are observed in aging and $\mathrm{AD}$.

Extensive evidence correlates advancing age with declines in overall bioenergetic function (Mecocci et al., 1994; Trifunovic et al., 2004; Kujoth et al., 2005; Navarro and Boveris, 2007; Boveris and Navarro, 2008; Swerdlow, 2011, 2012, 2014; Ross et al., 2013). Decreased glucose utilization via fluorodeoxyglucose (18F) positron emission tomography (FDG-PET) scan analysis is evident in brains from aged individuals (De Santi et al., 1995; Chetelat et al., 2013; Marano et al., 2013). Mitochondria play a prominent role in contributing to the overall state of age-associated bioenergetic decline. Aging mouse models show a continuous decrease in the ability to produce ATP via oxidative phosphorylation at the mitochondrial membrane, and specifically a reduction in the Vmax activities of Complexes I and IV of the electron transport chain (ETC) (Navarro and Boveris, 2007, 2010). Minimal changes to mitochondrial inner membrane permeability or F1-ATP-synthase activity are observed in these aging mouse models. Furthermore, the reduction in Complex I and IV Vmax activities correlates linearly with neurological performance and life span (Navarro and Boveris, 2004, 2007; Boveris and Navarro, 2008). Several studies of rats have shown that inhibiting cytochrome oxidase (COX-IV) results in impaired long term potentiation, further demonstrating the importance of mitochondrial bioenergetic flux in memory and learning (Parker et al., 1990; Bennett et al., 1992; Swerdlow and Kish, 2002). Aging also results in increased reactive oxygen species (ROS) production, a byproduct of dysfunctional mitochondria and oxidative stress (Shigenaga et al., 1994; Ames et al., 1995). Finally, accumulation of somatic mitochondrial DNA (mtDNA) mutations has been implicated as an upstream component in aging phenotypes (Doherty, 2003; Kujoth et al., 2005; Hiona et al., 2010).

Ample evidence indicates age-associated bioenergetic changes are exacerbated in AD populations. Several decades of FDG-PET analyses note a reduction in glucose utilization in $\mathrm{AD}$ subject brains (Frackowiak et al., 1981; Foster et al., 1983; Friedland et al., 1983). Analyses of mitochondria isolated from both brain and platelets show an impaired bioenergetic capacity in AD patients. More specifically, there are reductions in Complex I and IV Vmax activity in AD subjects, along with minimal differences in ATP-synthase activity (Mecocci et al., 1994; Maurer et al., 2000; Bosetti et al., 2002). Postmortem examination of AD brain tissue has revealed excessive oxidative stress and oxidative changes to mtDNA (Mecocci et al., 1994; Manczak et al., 2004; Onyango and Khan, 2006; Gibson et al., 2010). Pyruvate dehydrogenase and $\alpha$-ketoglutarate dehydrogenase are also impaired in $\mathrm{AD}$ subjects (Parker et al., 1990; Kish, 1997; Gibson et al., 2010; Swerdlow, 2012).

Although parental history is an $\mathrm{AD}$ risk factor, individuals with mothers afflicted with $\mathrm{AD}$ are more likely to develop $\mathrm{AD}$ than individuals whose fathers have AD (Edland et al., 1996; Mosconi et al., 2007; Honea et al., 2012). Children of mothers with AD have 
progressive reductions in brain glucose metabolism prior to any overt cognitive defect (Mosconi et al., 2007). Children of cognitively normal parents or fathers afflicted with $\mathrm{AD}$, on the other hand, do not show reductions in brain glucose utilization while phenotypically healthy (Mosconi et al., 2007). As mtDNA is maternally inherited, these data suggest mtDNA may influence AD risk by in part determining an individual's mitochondrial function and bioenergetic capacity.

The cytoplasmic hybrid (cybrid) technique is a useful way to observe the specific role of mtDNA within disease phenotypes. The technique utilizes the mtDNA contained within donor platelet samples and transfers it to cell lines depleted of endogenous mtDNA. This approach results in the creation of cell lines with an equivalent nuclear DNA background, but that vary in their mtDNA content (Swerdlow, 2002; Wilkins et al., 2014). AD cybrid lines, generated using neuroblastoma cell lines, have decreases in COX activity, ATP, mitochondrial calcium concentration, mitochondrial membrane potential, and glycolytic flux (Sheehan et al., 1997; Swerdlow et al., 1997; Ghosh et al., 1999; Silva et al., 2012, 2013). NFкB, MAPK, and AKT pathways are activated in AD cybrids, while active caspase- 3 and cytoplasmic cytochrome $c$ are elevated (Ghosh et al., 1999; Onyango et al., 2005; Silva et al., 2012, 2013; Wilkins et al., 2014). Finally, AD cybrids show increased amyloid beta production and mimic the effects of oxidative stress observed in aging and AD brains (Onyango et al., 2005). These cybrid studies indicate the contribution of mtDNA to diminished bioenergetic function and biochemical changes in $\mathrm{AD}$.

It remains to be seen whether bioenergetic dysfunction represents an upstream or downstream pathology in AD. The "mitochondrial cascade hypothesis," proposed in 2004, asserts that bioenergetic perturbations cause AD clinical and histologic changes (Swerdlow and Khan, 2004). Bioenergetic dysfunction can drive inflammation and, conversely, inflammation can also result in bioenergetic dysfunction. Next, we will review the interplay between these two AD-associated phenomena.

\section{RELATIONSHIP BETWEEN INFLAMMATION AND BIOENERGETIC DYSFUNCTION}

Inflammation has the potential to initiate bioenergetic perturbations. Microglia, the resident macrophages within the CNS, function to sense possible pathogen-associated molecular patterns (PAMPs) or damage-associated molecular patterns (DAMPs). Upon activation, microglia produce increased amounts of the reactive nitrogen species (RNS) nitric oxide (NO) due to an upregulation of inducible nitric oxide synthase (iNOS), and ROS due to an increase in NADPH oxidase (Babior, 2004; Di Filippo et al., 2010). The main function of these free radicals is to mitigate pathogens. However, surrounding cells are also subject to the effects of ROS and RNS. This damages DNA, lipids, and proteins, and can affect overall mitochondrial function. In one possible scheme, free radicals generated by microglia during chronic inflammation states damage mtDNA, which disrupts oxidative phosphorylation and further amplifies ROS/RNS production in a cyclical process (Balaban et al., 2005; Fukui and Moraes, 2008). This is exemplified by the finding that NO production inhibits mitochondrial respiration. The effect is mediated by direct competition of NO against oxygen binding to Complex
IV. In particular, astrocytes stimulated to produce NO showed evidence of inhibited mitochondrial respiration (Brown, 1997).

Conversely bioenergetic dysfunction, particularly at the level of the mitochondria, is known to induce inflammation. Inhibition of Complex I with rotenone or methyl-4-phenyl-1,2,3,6tetrahydropyridine (MPTP) induces inflammatory changes both in vitro and in vivo. Rotenone administration activates a human microglial cell line and stimulates the production of ROS (Shaikh and Nicholson, 2009). In a rat model, rotenone induces microglial activation in the striatum and substantia nigra. Microglial activation occurs prior to dopaminergic neuron loss in this model (Sherer et al., 2003). A separate study found that rotenonetriggered dopaminergic neuron loss occurs through an NADPH oxidase-dependent microglial response (Gao et al., 2003a). Microglial activation is found in various models of MPTP neurotoxicity. NADPH oxidase, to some extent, is required for MPTP neurotoxicity (Gao et al., 2003b; McGeer and McGeer, 2008; Long-Smith et al., 2009).

Further models associate mitochondrial dysfunction with inflammatory signaling. Inhibition of Complex I (rotenone) or Complex III (antimycin A) in bone marrow-derived macrophages induced IL- $1 \beta$ production, which was dependent on the nod-like receptor family pyrid domain containing 3 (NLRP3) inflammasome (Zhou et al., 2011). In this same study, concomitant rotenone administration with inhibition of mitophagy/autophagy pathways caused an accumulation of damaged mitochondria and ROS production with downstream IL-1 $\beta$ production (Zhou et al., 2011). Macrophages lacking mtDNA ( $\rho 0$ cells) are not able to activate caspase-1 in response to LPS and ATP (Nakahira et al., 2011). This study indicates the requirement for functional mitochondrial respiration in the activation of caspase- 1 and the NLRP3 inflammasome.

A further study utilized the cybrid model to generate cell lines with mtDNA from different haplogroups. mtDNA haplogroups represent distinct population origins through defined SNPs. This particular study compared the $\mathrm{H}$ haplogroup to the $\mathrm{J}$ haplogroup. The J haplogroup had significantly decreased expression of seven mitochondrial-encoded ETC components (MTND1, MT-ND2, MT-ND3, MT-ND4, MT-CO2, MT-CO3, and MT-ATP6) (Cristina Kenney et al., 2014). Cybrids generated from J haplogroup mtDNA donors had a reduced oxygen consumption rate (OCR), a reduced OCR to extracellular acidification rate (ECAR) ratio, and significantly reduced complement pathway and other inflammatory gene mRNA levels (such as IL-33). This novel study depicts the interplay between specific mtDNA sequences, bioenergetic function, and inflammation.

It is increasingly apparent that bioenergetic function and inflammation are interdependent processes. We further hypothesize the release of DAMPs that derive from mitochondria may at least, in part, drive inflammation in $\mathrm{AD}$.

\section{STERILE INFLAMMATION}

Given the striking lack of evidence for pathogen-induced inflammation in $\mathrm{AD}$, it is reasonable to hypothesize a significant role for non-pathogen initiated inflammation or sterile inflammation in the disease pathology. DAMPs, also referred to as alarmins, are endogenous molecules that are normally sequestered by the host 


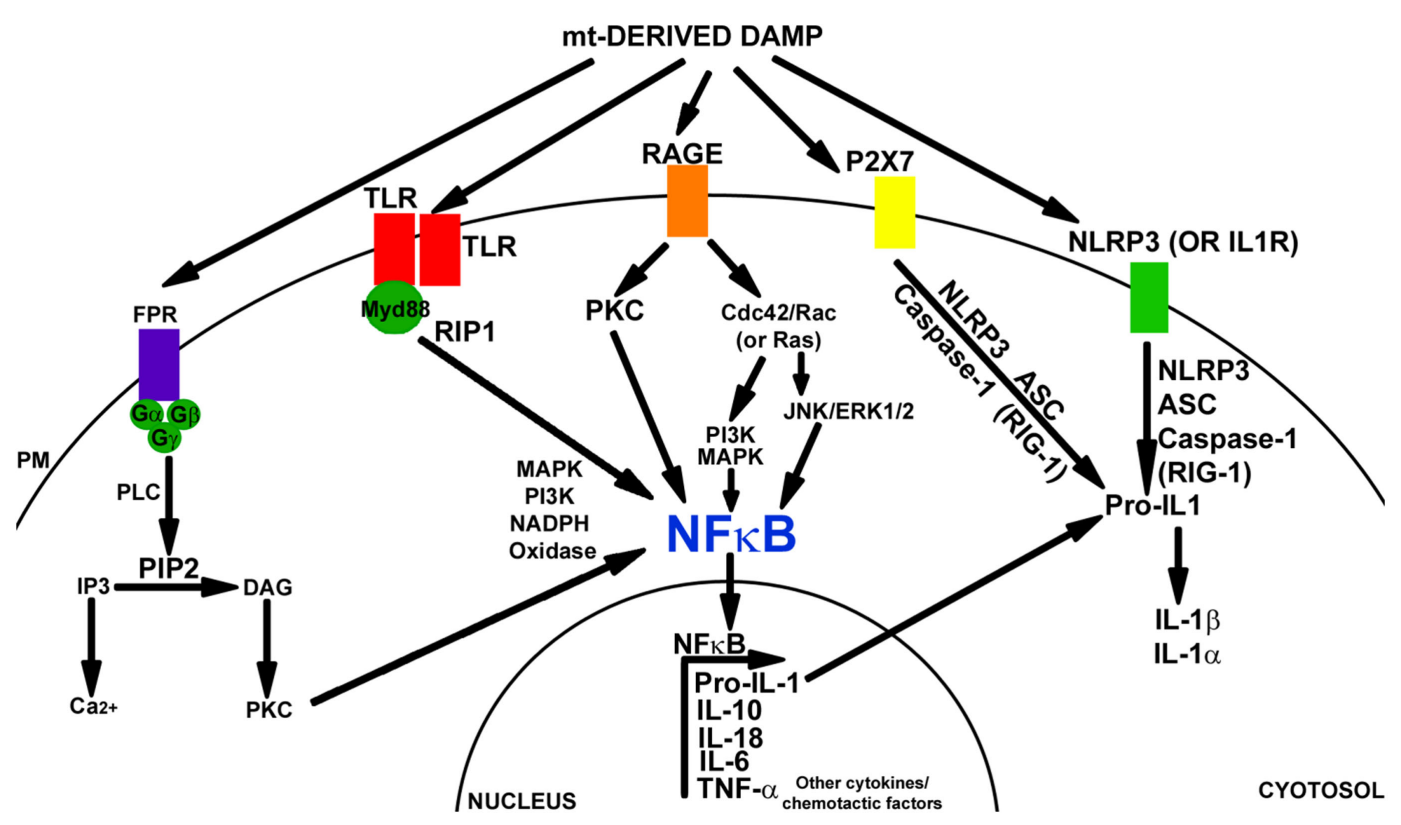

FIGURE 1 | Damage-associated molecular pattern signaling mechanisms. Mitochondrial components can induce a DAMP response through the activation of TLR, FPR, RAGE, P2X7, and/or the NALP3 inflammasome. FPR is a GCPR. FPR signaling is mediated through PLC, PIP2, IP3, and DAG. Downstream activation of PKC leads to signaling through MAPK, PI3K, and activation of NFKB and NAPDH oxidase. TLR receptors dimerize with Myd88 and can activate NFKB through RIP1 kinase, MAPK, or PI3K pathways. The TLR pathway also activates NADPH oxidase. RAGE receptor signaling activates PKC and CdC42/Rac (or Ras). Downstream PI3K, MAPK or JNK, and Erk1/2 are activated. This leads to $N F_{K} B$ activation (in addition to SP1 and AP1). P2X7 activation leads to NRLP3 inflammasome signaling. NLRP3 (or IL-1R) activation mediates inflammasome signaling through NLRP3, ACS, and caspase-1 (or RIG-1). Pro- $I L-1$ is cleaved into $I L-1 \beta$ and $I L-1 \alpha$. NFKB activation initiates transcription of Pro-IL-1, IL-10, IL-18, IL-6, TNF $\alpha$, along with many other cytokine and chemotactic factors. cell and are therefore recognized as danger signals. DAMPs are released during the death and rupture of host cells. These molecules initiate inflammatory signaling cascades, thus leading to sterile inflammation. DAMPs have been associated with traumatic brain injury, ischemia-reperfusion, atherosclerosis, arthritis, and systemic inflammatory response syndrome (SIRS) (Collins et al., 2004; Pullerits et al., 2005; Porto et al., 2006; Foell et al., 2007; Zhang et al., 2010; van Golen et al., 2013; Walko et al., 2014).

The inflammatory response stimulated by DAMPs is similar to the response induced by PAMPs. Typically, these molecules are recognized by a pattern recognition receptor (PRR), which leads to the activation of transcription factors such as NFKB and cytokine production. Despite this similarity, data suggest PRRs are able to discriminate between PAMPs and DAMPs through CD24SiglacG/10 signaling (Kaczmarek et al., 2013). Figure 1 depicts the pathways in which DAMP molecules can initiate inflammatory signaling.

\section{MITOCHONDRIAL COMPONENTS AS DAMPS}

Mitochondria presumably arose through the modification of a previously independent, respiratory competent prokaryotic cell. This is supported by the fact that mitochondria share numerous characteristics with bacteria. Several studies have examined the ability of whole mitochondrial extracts to induce inflammation. In particular, human plasmacytoid dendritic cells incubated with total mitochondrial extracts up-regulate IFN $\alpha$ expression (Julian et al., 2012). This requires the presence of mtDNA and toll-like receptor 9 (TLR9)/receptor for advanced glycation endproducts (RAGE) activation. Fractions from nuclear and cytoplasmic pools, on the other hand, do not induce IFN $\alpha$ expression. A separate study that treated human blood monocytes with total mitochondrial extracts found increased IL- 8 expression and secretion (Crouser et al., 2009). Again, treatment with nuclear or cytoplasmic fractions did not produce this result. In vivo and in vitro treatment with disrupted mitochondria induced polymorphonuclear leukocyte (PMN) migration and degranulation, calcium flux, MAPK activation, and cytokine production that included increased levels of matrix metalloproteinase-8 (MMP-8), IL-8, IL-6, and TNF $\alpha$ (Zhang et al., 2010). Human neutrophils treated with ruptured mitochondria showed increased calcium release, oxidative bursts, and chemotaxis (Julian et al., 2013). Overall, it is not surprising that a considerable number of molecules that derive from mitochondria act as DAMPs. These molecules are shown in Table 2 and are reviewed below.

\section{Mitochondrial DNA}

Mitochondrial DNA shares many characteristics with bacterial DNA. It is circular in structure, lacks histones, and contains unmethylated $\mathrm{CpG}$ repeats and bound formyl-peptides. The mitochondrial genome encodes 11 components of the ETC and two subunits of ATP synthase. The nuclear genome and mitochondrial genome work in an organized and concerted manner to maintain a functional ETC. mtDNA serves as a DAMP molecule in trauma patients and in SIRS. In particular, the concentration of mtDNA 
Table 2 | Mitochondrial-derived DAMP molecules.

\begin{tabular}{|c|c|c|c|c|}
\hline $\begin{array}{l}\text { Mitochondrial derived-DAMP } \\
\text { molecule }\end{array}$ & $\begin{array}{l}\text { Receptor } \\
\text { activated }\end{array}$ & $\begin{array}{l}\text { Proteins activated/ } \\
\text { up-regulated }\end{array}$ & Cytokines produced & Reference \\
\hline mtDNA & TLR & MAPK, MMP-8, NFKB & IL-1 $\beta$, IL-6, IL-8, MCP-1, TNF $\alpha$ & (Oka et al., 2012; Zhang et al., 2014) \\
\hline Cardiolipin & NA & ICAM, VCAM & NA & (Man et al., 2014) \\
\hline ATP & P2X7, NLRP3 & MMP9 & $\begin{array}{l}\text { CCL2, CCL7, CXCL2, IL-1 } \\
\text { IL-6, IL-8, IL-10, IL-12, IL-18, } \\
\text { INF } \gamma, \text { TNF } \alpha\end{array}$ & $\begin{array}{l}\text { (Gourine et al., 2007; Piccini et al., } \\
\text { 2008; Riteau et al., 2010; Kurashima } \\
\text { et al., 2012; Cauwels et al., 2014) }\end{array}$ \\
\hline fMLP & FPR & iNOS, NFKB, MAPK, PI3K & IL-1 $\beta, I L-8$ & (Pan et al., 2000) \\
\hline TFAM+/- mtDNA & TLR, RAGE & $\mathrm{NF} \kappa \mathrm{B}, \mathrm{PI} 3 \mathrm{~K}$ & IL-1 $\beta$, IL-6, IL-8, TNF $\alpha$ & (Julian et al., 2013; Little et al., 2014) \\
\hline Cytochrome c & NA & $N F_{\kappa B}$ & $\begin{array}{l}\text { IL-6,MCP-1, MIP-2, MIP-1 } \alpha \\
\text { RANTES, TNF } \alpha\end{array}$ & (Pullerits et al., 2005) \\
\hline HMGB1 & TLR, RAGE & $\begin{array}{l}\text { ERK, ICAM, JNK, NFKB, } \\
\text { MAPK, SP1, VCAM }\end{array}$ & IL-8, MCP-1, PAI-1, tPA, TNF $\alpha$ & $\begin{array}{l}\text { (Scaffidi et al., 2002; Fiuza et al., } \\
\text { 2003; Mazarati et al., 2011) }\end{array}$ \\
\hline
\end{tabular}

NA, not available.

circulating in plasma predicts mortality in trauma patients (Zhang et al., 2010; Nakahira et al., 2013).

Several studies have directly tested the ability of mtDNA to induce inflammation. In a recent study, mouse primary astrocytes were transfected with oxidant-initiated, degraded mitochondrial polynucleotides (DeMPs) (Mathew et al., 2012). This lead to the production of IL-6, MCP-1, TNF $\alpha$, and IL-1 $\beta$. DeMPs can also be detected in human CSF samples. In human PMNs, mtDNA induces MAPK activation and IL- 8 production (Zhang et al., 2010). mtDNA also induces inflammation in vivo. Intraarticular injection of mtDNA in mice induces arthritis and TNF $\alpha$ expression (Collins et al., 2004). The lungs of rats receiving intravenous injection of mtDNA exhibited up-regulation of TLR9, NFкB, TNF $\alpha$, IL-6, and IL-10 (Zhang et al., 2014). These results were not recapitulated upon injection of nuclear DNA. A separate study demonstrated mtDNA that eludes autophagy can induce inflammation (Oka et al., 2012). Here, mice with cardiac-specific deletion of DNAse II underwent pressure overload, which allowed the release of mtDNA while subsequently inhibiting its degradation. Increased IL- $1 \beta$ and IL- 6 were observed. Outcomes in these mice were improved following the genetic ablation of TLR9. Overall, in various cell and tissue types mtDNA induces inflammatory signaling and cytokine production through common mechanisms.

\section{Mitochondrial transcription factor A}

Mitochondrial transcription factor A (TFAM) binds to mtDNA to initiate its transcription. Beyond its function in transcription of mtDNA, TFAM can also be released from damaged and dying cells, where it can act as a DAMP molecule. Specifically, treatment of human peripheral blood monocytes, THP-1 monocytic cells, or primary microglia from autopsy patients with TFAM and IFN $\gamma$ caused cell death in neuronal cell lines co-cultured with glial cells. It was found that activation of the JNK pathway was necessary for these results (Little et al., 2014). Stimulation of THP-1 monocytes with TFAM alone elevated expression of IL-1 $\beta$, IL6 , and IL-8, and this was enhanced by the addition of IFN $\gamma$.
An additional study found that TFAM alone or in combination with formyl-peptides induced IL-8 release from human blood monocytes in a formyl peptide receptor (FPR)-dependent manner (Crouser et al., 2009).

The combination of TFAM bound to mtDNA can also induce inflammation (Julian et al., 2012, 2013). This was demonstrated in human plasmacytoid dendritic cells, which up-regulated IFN $\alpha$ expression and release upon exposure to TFAM-bound mtDNA. In this study, inhibition of RAGE and TLR9 inhibited IFN $\alpha$ expression. PI3K, ERK, and NFKB signaling were also implicated.

Mouse splenocytes treated with a combination of TFAM and CpG-enriched mtDNA released TNF $\alpha$ in a TLR9 and RAGEdependent manner (Julian et al., 2013). PI3K and NFкB were also required for TNF $\alpha$ expression. Thus, TFAM can induce inflammation either alone or in combination with other mitochondrial components.

\section{Cardiolipin}

Mitochondrial lipids also have prokaryotic features. Cardiolipin is a unique lipid found in bacteria and the mitochondrial inner membrane. Cardiolipin is essential to mitochondrial function. Cardiolipin also acts as a mitochondrial-derived DAMP molecule. Anti-cardiolipin antibodies are found in some autoimmune diseases, including lupus (Ishii et al., 1990). Further, treatment of human monocyte-derived macrophages with oxidized cardiolipin induced the expression of intracellular adhesion molecule (ICAM1, also known as CD54) and vascular cell adhesion molecule (VCAM-1, also known as CD106) (Wan et al., 2014). Non-oxidized cardiolipin failed to elicit similar responses. While cardiolipin has the potential to induce inflammation and act as a DAMP molecule, at this time there is little direct evidence to suggest it commonly functions in this capacity.

\section{Cytochrome c}

Cytochrome $c$ is a small protein that is tethered by cardiolipin to the inner mitochondrial membrane. It serves as an electron 
donor and acceptor during oxidative phosphorylation. The release of cytochrome $c$ from mitochondria induces apoptosis, while its extracellular release initiates a DAMP response. Intra-articular injection of cytochrome $c$ in mice induces arthritis (Pullerits et al., 2005). In addition, exposing mouse splenocytes to exogenous cytochrome $c$ activates NFкB as well as TNF $\alpha$, IL-6, macrophage inflammatory proteins (MIP- $2 \alpha$ or CXCL2; MIP- $1 \alpha$ or CCL3), MCP-1, and RANTES (regulated on activation, normal $\mathrm{T}$ cell expressed) production. Circulating cytochrome $c$ can be measured in patients with liver injury, SIRS, and myocardial infarction (Krysko et al., 2011). Similar to cardiolipin, antibodies against cytochrome $c$ are found in lupus patients (Mamula et al., 1990).

\section{Adenosine triphosphate}

The main function of mitochondria in many cell types is to produce ATP through oxidative phosphorylation. A release of ATP occurs during cell death through either an active mechanism prior to loss of cell membrane integrity, or via a passive process after cell membranes become permeable (Zitvogel et al., 2010). ATP facilitates the recruitment of macrophages and activation of the NLRP3 inflammasome through P2X7 purinergic receptors. In a mouse model of 2,4,6-trinitrobenzene sulfonic acid (TNBS) induced-colitis, genetic knockout of $\mathrm{P} 2 \mathrm{X} 7$ in mast cells reduced intestinal inflammation and IL-6, TNF $\alpha$, MCP-1, MCP-3, and MIP- $2 \alpha$ cytokine production (Kurashima et al., 2012). Inhibition of ADP-responsive $\mathrm{P} 2 \mathrm{Y}$ receptors (P2Y1 and $\mathrm{P} 2 \mathrm{Y} 12$ ) had no effect on inflammation observed in this model.

Using LPS-induced shock in mice, a separate study demonstrated a requirement for extracellular ATP in inflammation (Cauwels et al., 2014). This study used an ATP degrading enzyme, apyrase, to show extracellular release of ATP is required for inflammation and IL- $1 \beta, \mathrm{TNF} \alpha$, and IL-10 cytokine production. In this study, genetic ablation of $\mathrm{P} 2 \mathrm{X} 7$ receptors also mitigated cytokine production (Riteau et al., 2010). Conversely, when ATP- $\gamma$ S (a stable ATP derivate) was administered, inflammation was enhanced.

Within the CNS, extracellular ATP can serve as a DAMP molecule and also plays a role in the regulation of body temperature, cardiovascular function, and respiratory control (Gourine et al., 2007). As a DAMP molecule, ATP initiates TNF $\alpha$ release from cultured rat microglia in a calcium-dependent manner (Hide et al., 2000). Extracellular ATP treatment of microglia enhanced expression of MAPK and ERK, and inhibition of these pathways prevented production of $\mathrm{TNF} \alpha$. Primary rat cortical astrocytes treated with LPS release TNF $\alpha$, while ATP treatment alone has no effect (Kucher and Neary, 2005).

In vivo injection of LPS into rat striatum activates $\mathrm{P} 2 \mathrm{X} 7$ receptors (Choi et al., 2007). Blocking these receptors inhibits MAPK and $\mathrm{NF}_{\mathrm{K}} \mathrm{B}$ activation, and inhibits the production of COX2, IL-1 $\beta$, IL-6, IL-12, and TNF $\alpha$. Other studies have shown a differential effect of ATP on inflammation. ATP-induced TNF $\alpha$ release in microglia cells was found to protect co-cultured neurons exposed to glutamate (Suzuki et al., 2004).

In one study, injection of LPS into the anterior hypothalamus of rabbits induced an extracellular ATP release (Gourine et al., 2007). The concentration and timing of this extracellular ATP release appeared to associate with a thermoregulatory febrile response (Gourine et al., 2007).

\section{Formyl-peptides}

Formyl-peptides are found in both mitochondrial compartments and bacteria. In particular, formyl-methionine-leucinephenylalanine (fMLP) is known to act as a DAMP molecule. In human peripheral blood monocytes, fMLP induces NFKB activation and IL- $1 \beta$ production in a PI3K-dependent manner (Pan et al., 2000). Similar results were observed in murine peritoneal macrophages. fMLP stimulation led to activation of NFKB, PI3K, and MAPK pathways. Furthermore, iNOS expression and NO production were increased, an effect that depended on L-arginine (Sodhi and Biswas, 2002).

In PMN cells, fMLP results in calcium release and chemotaxis (Raoof et al., 2010). fMLP also induces inflammation in microglial cultures. Mixed cultures of neurons and glia stimulated with fMLP showed selective dopaminergic neuron loss and decreased dopamine uptake (Gao et al., 2008). Pharmacologic inhibition or genetic ablation of NADPH oxidase blocked fMLP toxicity. fMLP-related microglial activation was associated with changes in morphology, MHC II expression, and extracellular superoxide production. Formyl-peptides, specifically those with the sequence fMLP, therefore, initiate inflammation in peripheral and CNS cell models.

\section{High mobility group box 1}

High mobility group box 1 is normally considered a nuclear protein, however, under both normal and pathological conditions it localizes to mitochondria (Stumbo et al., 2008; Tang et al., 2010). The oxidation state of high mobility group box 1 (HMGB1) may influence its cellular localization (Tang et al., 2010). In the nucleus, HMGB1 functions to regulate transcription through interactions with histones and transcription factors. It also functions as a cytokine. In mitochondria, HMGB1 regulates mitochondrial "quality control" (Tang et al., 2010). Immune cells (such as macrophages) actively secrete HMGB1 during inflammation (Andersson and Tracey, 2011). Recent studies have also depicted the DAMP function of HMGB1. In mice, intracerebroventricular injection of HMGB1 caused memory deficits through TLR4 and RAGE-dependent pathways (Mazarati et al., 2011).

High mobility group box 1 also mediates inflammation in vitro. Necrotic mouse fibroblast cells release HMGB1, stimulating inflammatory changes such as increased $\mathrm{TNF} \alpha$ production via NFkB (Scaffidi et al., 2002). Indeed, necrotic fibroblast cells derived from HMGB1 null mice are not capable of inducing inflammation. Exogenous incubation of human microvascular endothelium cells with HMGB1 induces expression of ICAM-1, VCAM-1, RAGE, $\mathrm{TNF} \alpha, \mathrm{IL}-8$, MCP-1, plasminogen activator inhibitor-1 (PAI-1), and tissue plasminogen activator (tPA) (Fiuza et al., 2003). Cell signaling pathways and transcription factors that are activated include MAPK, ERK, JNK, NFKB, and SP1.

\section{MECHANISMS FOR MITOCHONDRIAL-DERIVED DAMP RELEASE}

Specific mitochondrial components clearly act as DAMP molecules. Beyond this, total mitochondrial extracts induce inflammation in several cell types (Crouser et al., 2009; Zhang et al., 2010; Julian et al., 2012, 2013). There is mounting evidence in the literature supporting mechanisms in which mitochondrial components (either as part of whole mitochondria or as specific molecules) 
can be released from cells. For example, mitochondria that escape autophagy (specifically, mitophagy) have the potential to stimulate an inflammatory response (Oka et al., 2012). A recent study showed that retinal ganglion cells shed mitochondria at the optic nerve head (Davis et al., 2014). Mitochondria shed by these neurons are then internalized by surrounding astrocytes and degraded. The authors of the study referred to this process as transmitophagy, or transcellular degradation of mitochondria. This process is also suspected to occur in other parts of the CNS, as similar accumulations of degrading mitochondria are found in superficial layers of the cerebral cortex alongside neurites. Finally, extracellular release of mitochondrial components could be a consequence of cell death pathways, such as necrosis or, possibly necroptosis (Kaczmarek et al., 2013).

\section{EVIDENCE FOR MITOCHONDRIAL-DERIVED DAMPS IN AD PATHOLOGY}

As discussed above, several mitochondrial components can act as DAMP molecules and evoke inflammatory signaling cascades. Here, we discuss relevant data, which suggest a role for mitochondrial DAMPs in AD pathology.

\section{DAMP signaling in AD}

Inflammasomes, particularly NLRP3 (or NALP3), have recently generated interest in the AD research field (Shaftel et al., 2008). Several components comprise the NLRP3 inflammasome including NLR protein, ASC adaptor protein, and pro-caspase-1. Retinoic acid inducible gene-1 (RIG-1) is another potential component of the inflammasome. Upon activation, the NLR protein activates transcription of pro-IL- $1 \beta$ and the formation of the NLRP3 inflammasome complex. After this, the NLRP3 inflammasome cleaves and activates pro-IL-1 $\beta$ and downstream molecules can be activated. Inflammasome signaling has been extensively reviewed elsewhere (Latz et al., 2013). Current data suggest IL-1 $\beta$ polymorphisms may associate with $\mathrm{AD}$ risk, although caspase-1 polymorphisms do not (Griffin et al., 2000; McGeer and McGeer, 2001; Shaftel et al., 2008; Vazquez-Higuera et al., 2010).

IL-1 $\beta$ levels are increased in CSF and serum from AD patients (Cacabelos et al., 1991; Blum-Degen et al., 1995; Licastro et al., 2000). Furthermore, IL-1 is found in microglia surrounding plaques in postmortem AD brain tissue (Griffin et al., 1989). IL-1 $\beta$ experimentally induces the disruption of the $\mathrm{BBB}$ and leukocyte recruitment to the CNS while also blocking LTP in the hippocampus (Shaftel et al., 2008). Elevated expression of active caspase-1 has also been detected in AD brain tissue (Heneka et al., 2013). RIG-1, a component of inflammasome signaling, is elevated in plasma and temporal cortex in mild cognitive impairment (MCI, frequently a precursor syndrome of AD) subjects (de Rivero Vaccari et al., 2014) Therefore, many lines of evidence suggest the NLRP3 inflammasome is relevant to AD.

Toll like receptors may also play a pivotal role in AD. Specific TLR9 polymorphisms have been associated with a decreased $\mathrm{AD}$ risk, while specific TLR4 polymorphisms have been associated with an increased risk (Balistreri et al., 2008; Wang et al., 2011, 2013). There is some conflict in the literature regarding the association of TLR2 genetic polymorphisms in AD (Yu et al., 2011a,b). In blood (PBMCs specifically) and brain tissue from AD patients, TLR2 and TLR4 are increased (Liu et al., 2005; Walter et al., 2007; Letiembre et al., 2009; Zhang et al., 2012). TLR activation leads to receptor dimerization at the plasma membrane with the adaptor protein MyD88, activation of the RIP1 kinase, and downstream signaling to NFKB and MAPK. Changes in levels of IL-6, IL-8, IL-12, and TNF $\alpha$ have been reported. Similar changes are observed in AD (Singh and Guthikonda, 1997; Swardfager et al., 2010; Cojocaru et al., 2011; Alsadany et al., 2013). While a lack of data exists regarding MyD88 in human AD patients, in one $\mathrm{AD}$ mouse model genetic ablation of MyD88 was found to mitigate microglial activation and amyloid beta toxicity (Lim et al., 2011).

Formyl peptide receptors are seven transmembrane domainconfigured $\mathrm{G}$ protein-coupled receptors (GPCRs). Activation of FPRs can induce cell adhesion, chemotaxis, ROS release, production of pro-inflammatory cytokines, and phagocytosis. Upon stimulation, FPRs bind G proteins and execute the activation of signaling pathways including, PI3K, IPR3 (which mediates ER calcium efflux), and NFKB. This leads to downstream NADPH oxidase respiratory flux and cytokine production. FPRs have attracted interest in $\mathrm{AD}$ due to the binding capacity of the amyloid beta peptide (Verdier et al., 2004). While the downstream effectors of FPR signaling are implicated in $\mathrm{AD}$ histopathology, no direct evidence of activation of FPRs in AD patients has currently been published.

RAGE was initially identified in lung tissue, where it was found to bind advanced glycation endproducts (AGEs) (Xie et al., 2013). Numerous cell processes are activated through RAGE signaling including cell motility, proliferation, autophagy, inflammation, and apoptosis. Inflammatory signaling cascades activated downstream of RAGE include MAPK, JNK, and NFאB. Production of pro-inflammatory cytokines, including IL-6, IL-8, TNF $\alpha$, and COX2, are mediated through these signaling cascades. Several mitochondrial-derived DAMPs can induce RAGE activation, including the combination of TFAM and CpG mtDNA (Julian et al., 2013). RAGE also binds amyloid beta, a finding that suggests a possible association between RAGE and AD (Verdier et al., 2004; Xie et al., 2013). Microglia from AD subjects show increased RAGE expression (Lue et al., 2001).

\section{Mitochondrial-derived DAMPs in AD}

Few mitochondrial-derived DAMP molecules have been measured in actual AD patients. CSF concentrations of cell-free circulating mtDNA are reduced in AD patients (Podlesniy et al., 2013). This finding is of interest because while amyloid beta levels are high in AD brain and plasma, CSF levels of amyloid beta are decreased (Mehta et al., 2000; Wallin et al., 2006; Buchhave et al., 2012). How CSF concentrations of molecules (such as proteins and DNA) relate to their respective brain concentrations at this time, therefore, is incompletely understood. Another study that reported DeMPs induce inflammation in primary mouse astrocytes (Mathew et al., 2012) also reported the detection of DeMPs in human CSF and plasma samples. However, no current data are available to show whether DeMP levels in $\mathrm{AD}$ subjects exceeds levels in non-demented control subjects.

Cerebral spinal fluid cytochrome $c$ levels are increased in MCI patients, and to some extent can predict conversion to AD. More specifically, cytochrome $c$ levels are increased in MCI subjects who ultimately convert to the AD clinical phenotype (Papaliagkas et al., 2009). 


\section{CONCLUSION}

Inflammation and bioenergetic dysfunction are important pathological phenomena in AD. Inflammation and bioenergetic dysfunction can exhibit a cyclical relationship. Given the relationship between these two pathologies and their interdependence on mitochondria we hypothesize that DAMPs derived from mitochondria contribute to the initiation of inflammation in AD. The release of mitochondrial components could occur through necrotic cell death, transcellular mitophagy, or other currently undefined mechanisms. The presence of inflammation may, in turn, further perturb brain bioenergetic function. Basic evidence for a DAMP response in AD is currently supported by existing literature, although further investigation is needed to specifically define the contribution of mitochondrial DAMPs to chronic brain inflammation in this disease.

\section{ACKNOWLEDGMENTS}

This work was supported by the University of Kansas Alzheimer's Disease Center (P30AG035982), the Frank and Evangeline Thompson Alzheimer's Treatment Program Fund, the Hugh and Betty Libby Foundation, the Greater Kansas City Automobile Dealers Association, the Gene and Marge Sweeney Chair, KU ADC Pilot program, Landon Center for Aging, Frontiers the Heartland Institute for Clinical and Translational Research, and the KUMC Biomedical Research Training Program.

\section{REFERENCES}

Akiyama, H. (1994). Inflammatory response in Alzheimer's disease. Tohoku J. Exp. Med. 174, 295-303. doi:10.1620/tjem.174.295

Akiyama, H., Barger, S., Barnum, S., Bradt, B., Bauer, J., Cole, G. M., et al. (2000a). Inflammation and Alzheimer's disease. Neurobiol. Aging 21, 383-421. doi:10.1016/S0197-4580(00)00124-X

Akiyama, H., Arai, T., Kondo, H., Tanno, E., Haga, C., and Ikeda, K. (2000b). Cell mediators of inflammation in the Alzheimer disease brain. Alzheimer Dis. Assoc. Disord. 14(Suppl. 1), S47-S53. doi:10.1097/00002093-200000001-00008

Alsadany, M. A., Shehata, H. H., Mohamad, M. I., and Mahfouz, R. G. (2013). Histone deacetylases enzyme, copper, and IL-8 levels in patients with Alzheimer's disease. Am. J. Alzheimers Dis. Other Demen. 28, 54-61. doi:10.1177/1533317512467680

Ames, B. N., Shigenaga, M. K., and Hagen, T. M. (1995). Mitochondrial decay in aging. Biochim. Biophys. Acta 1271, 165-170. doi:10.1016/0925-4439(95) 00024-X

Andersson, U., and Tracey, K. J. (2011). HMGB1 is a therapeutic target for sterile inflammation and infection. Annu. Rev. Immunol. 29, 139-162. doi:10.1146/ annurev-immunol-030409-101323

Babior, B. M. (2004). NADPH oxidase. Curr. Opin. Immunol. 16, 42-47. doi:10. 1016/j.coi.2003.12.001

Balaban, R. S., Nemoto, S., and Finkel, T. (2005). Mitochondria, oxidants, and aging. Cell 120, 483-495. doi:10.1016/j.cell.2005.02.001

Balistreri, C. R., Grimaldi, M. P., Chiappelli, M., Licastro, F., Castiglia, L., Listi, F., et al. (2008). Association between the polymorphisms of TLR4 and CD14 genes and Alzheimer's disease. Curr. Pharm. Des. 14, 2672-2677. doi:10.2174/ 138161208786264089

Bennett, M. C., Diamond, D. M., Stryker, S. L., Parks, J. K., and Parker, W. D. Jr. (1992). Cytochrome oxidase inhibition: a novel animal model of Alzheimer's disease. J. Geriatr. Psychiatry Neurol. 5, 93-101. doi:10.1177/002383099200500206

Block, M. L., Zecca, L., and Hong, J. S. (2007). Microglia-mediated neurotoxicity: uncovering the molecular mechanisms. Nat. Rev. Neurosci. 8, 57-69. doi: $10.1038 / \mathrm{nrn} 2038$

Blum-Degen, D., Muller, T., Kuhn, W., Gerlach, M., Przuntek, H., and Riederer, P. (1995). Interleukin-1 beta and interleukin-6 are elevated in the cerebrospinal fluid of Alzheimer's and de novo Parkinson's disease patients. Neurosci. Lett. 202, 17-20. doi:10.1016/0304-3940(95)12192-7

Bosetti, F., Brizzi, F., Barogi, S., Mancuso, M., Siciliano, G., Tendi, E. A., et al. (2002). Cytochrome c oxidase and mitochondrial F1F0-ATPase (ATP synthase) activities in platelets and brain from patients with Alzheimer's disease. Neurobiol. Aging 23, 371-376. doi:10.1016/S0197-4580(01)00314-1

Boveris, A., and Navarro, A. (2008). Brain mitochondrial dysfunction in aging. IUBMB Life 60, 308-314. doi:10.1002/iub.46

Breitner, J. C., Gau, B. A., Welsh, K. A., Plassman, B. L., McDonald, W. M., Helms, M. J., et al. (1994). Inverse association of anti-inflammatory treatments and Alzheimer's disease: initial results of a co-twin control study. Neurology 44, 227-232. doi:10.1212/WNL.44.2.227

Brown, G. C. (1997). Nitric oxide inhibition of cytochrome oxidase and mitochondrial respiration: implications for inflammatory, neurodegenerative and ischaemic pathologies. Mol. Cell. Biochem. 174, 189-192. doi:10.1023/A:1006800322719

Buchhave, P., Minthon, L., Zetterberg, H., Wallin, A. K., Blennow, K., and Hansson, O. (2012). Cerebrospinal fluid levels of beta-amyloid 1-42, but not of tau, are fully changed already 5 to 10 years before the onset of Alzheimer dementia. Arch. Gen. Psychiatry 69, 98-106. doi:10.1001/archgenpsychiatry.2011.155

Cacabelos, R., Barquero, M., Garcia, P., Alvarez, X. A., and Varela de Seijas, E. (1991). Cerebrospinal fluid interleukin-1 beta (IL-1 beta) in Alzheimer's disease and neurological disorders. Methods Find. Exp. Clin. Pharmacol. 13, 455-458.

Cagnin, A., Brooks, D. J., Kennedy, A. M., Gunn, R. N., Myers, R., Turkheimer, F. E., et al. (2001). In-vivo measurement of activated microglia in dementia. Lancet 358, 461-467. doi:10.1016/S0140-6736(01)05625-2

Cartier, L., Hartley, O., Dubois-Dauphin, M., and Krause, K. H. (2005). Chemokine receptors in the central nervous system: role in brain inflammation and neurodegenerative diseases. Brain Res. Brain Res. Rev. 48, 16-42. doi:10.1016/j. brainresrev.2004.07.021

Cauwels, A., Rogge, E., Vandendriessche, B., Shiva, S., and Brouckaert, P. (2014). Extracellular ATP drives systemic inflammation, tissue damage and mortality. Cell Death Dis. 5, e1102. doi:10.1038/cddis.2014.70

Chetelat, G., Landeau, B., Salmon, E., Yakushev, I., Bahri, M. A., Mezenge, F., et al. (2013). Relationships between brain metabolism decrease in normal aging and changes in structural and functional connectivity. Neuroimage 76, 167-177. doi:10.1016/j.neuroimage.2013.03.009

Choi, H. B., Ryu, J. K., Kim, S. U., and McLarnon, J. G. (2007). Modulation of the purinergic $\mathrm{P} 2 \mathrm{X} 7$ receptor attenuates lipopolysaccharide-mediated microglial activation and neuronal damage in inflamed brain. J. Neurosci. 27, 4957-4968. doi:10.1523/JNEUROSCI.5417-06.2007

Cojocaru, I. M., Cojocaru, M., Miu, G., and Sapira, V. (2011). Study of interleukin-6 production in Alzheimer's disease. Rom. J. Intern. Med. 49, 55-58.

Collins, L. V., Hajizadeh, S., Holme, E., Jonsson, I. M., and Tarkowski, A. (2004) Endogenously oxidized mitochondrial DNA induces in vivo and in vitro inflammatory responses. J. Leukoc. Biol. 75, 995-1000. doi:10.1189/jlb.0703328

Cristina Kenney, M., Chwa, M., Atilano, S. R., Falatoonzadeh, P., Ramirez, C., Malik, D., et al. (2014). Inherited mitochondrial DNA variants can affect complement, inflammation and apoptosis pathways: insights into mitochondrial-nuclear interactions. Hum. Mol. Genet. 23, 3537-3551. doi:10.1093/hmg/ddu065

Crocker, P. R., and Varki, A. (2001). Siglecs in the immune system. Immunology 103, 137-145. doi:10.1046/j.0019-2805.2001.01241.x

Crouser, E. D., Shao, G., Julian, M. W., Macre, J. E., Shadel, G. S., Tridandapani, S., et al. (2009). Monocyte activation by necrotic cells is promoted by mitochondrial proteins and formyl peptide receptors. Crit. Care Med. 37, 2000-2009. doi:10.1097/CCM.0b013e3181a001ae

Davis, C. H., Kim, K. Y., Bushong, E. A., Mills, E. A., Boassa, D., Shih, T., et al. (2014). Transcellular degradation of axonal mitochondria. Proc. Natl. Acad. Sci. U.S.A. 111, 9633-9638. doi:10.1073/pnas.1404651111

de Rivero Vaccari, J. P., Brand, F. J. III, Sedaghat, C., Mash, D. C., Dietrich, W. D., and Keane, R. W. (2014). RIG-1 receptor expression in the pathology of Alzheimer's disease. J. Neuroinflammation 11, 67. doi:10.1186/1742-2094-11-67

De Santi, S., de Leon, M. J., Convit, A., Tarshish, C., Rusinek, H., Tsui, W. H., et al. (1995). Age-related changes in brain: II. Positron emission tomography of frontal and temporal lobe glucose metabolism in normal subjects. Psychiatr. Q. 66, 357-370. doi:10.1007/BF02238755

Di Filippo, M., Chiasserini, D., Tozzi, A., Picconi, B., and Calabresi, P. (2010). Mitochondria and the link between neuroinflammation and neurodegeneration. $J$ Alzheimers Dis. 20(Suppl. 2), S369-S379. doi:10.3233/JAD-2010-100543

Doherty, T. J. (2003). Invited review: aging and sarcopenia. J. Appl. Physiol. 95, 1717-1727. doi:10.1152/japplphysiol.00347.2003

Edland, S. D., Silverman, J. M., Peskind, E. R., Tsuang, D., Wijsman, E., and Morris, J. C. (1996). Increased risk of dementia in mothers of Alzheimer's disease cases 
evidence for maternal inheritance. Neurology 47, 254-256. doi:10.1212/WNL. 47.1.254

Engelhart, M. J., Geerlings, M. I., Meijer, J., Kiliaan, A., Ruitenberg, A., van Swieten, J. C., et al. (2004). Inflammatory proteins in plasma and the risk of dementia: the Rotterdam study. Arch. Neurol. 61, 668-672. doi:10.1001/archneur.61.5.668

Fiuza, C., Bustin, M., Talwar, S., Tropea, M., Gerstenberger, E., Shelhamer, J. H., et al. (2003). Inflammation-promoting activity of HMGB1 on human microvascular endothelial cells. Blood 101, 2652-2660. doi:10.1182/blood-2002-05-1300

Foell, D., Wittkowski, H., and Roth, J. (2007). Mechanisms of disease: a "DAMP" view of inflammatory arthritis. Nat. Clin. Pract. Rheumatol. 3, 382-390. doi:10. 1038/ncprheum0531

Foster, N. L., Chase, T. N., Fedio, P., Patronas, N. J., Brooks, R. A., and Di Chiro, G. (1983). Alzheimer's disease: focal cortical changes shown by positron emission tomography. Neurology 33, 961-965. doi:10.1212/WNL.33.8.961

Frackowiak, R. S., Pozzilli, C., Legg, N. J., Du Boulay, G. H., Marshall, J., Lenzi, G. L., et al. (1981). Regional cerebral oxygen supply and utilization in dementia. A clinical and physiological study with oxygen-15 and positron tomography. Brain 104(Pt 4), 753-778. doi:10.1093/brain/104.4.753

Friedland, R. P., Budinger, T. F., Ganz, E., Yano, Y., Mathis, C. A., Koss, B., et al. (1983). Regional cerebral metabolic alterations in dementia of the Alzheimer type: positron emission tomography with [18F]fluorodeoxyglucose. J. Comput. Assist. Tomogr. 7, 590-598. doi:10.1097/00004728-198308000-00003

Fukui, H., and Moraes, C. T. (2008). The mitochondrial impairment, oxidative stress and neurodegeneration connection: reality or just an attractive hypothesis? Trends Neurosci. 31, 251-256. doi:10.1016/j.tins.2008.02.008

Gao, H. M., Liu, B., and Hong, J. S. (2003a). Critical role for microglial NADPH oxidase in rotenone-induced degeneration of dopaminergic neurons. J. Neurosci. 23, 6181-6187. doi:10.1186/1742-2094-5-21

Gao, H. M., Liu, B., Zhang, W., and Hong, J. S. (2003b). Critical role of microglial NADPH oxidase-derived free radicals in the in vitro MPTP model of Parkinson's disease. FASEB J. 17, 1954-1956. doi:10.1096/fi.03-0109fje

Gao, X., Hu, X., Qian, L., Yang, S., Zhang, W., Zhang, D., et al. (2008). Formyl-methionyl-leucyl-phenylalanine-induced dopaminergic neurotoxicity via microglial activation: a mediator between peripheral infection and neurodegeneration? Environ. Health Perspect. 116, 593-598. doi:10.1289/ehp.11031

Ghosh, S. S., Swerdlow, R. H., Miller, S. W., Sheeman, B., Parker, W. D. Jr., and Davis, R. E. (1999). Use of cytoplasmic hybrid cell lines for elucidating the role of mitochondrial dysfunction in Alzheimer's disease and Parkinson's disease. Ann. N. Y. Acad. Sci. 893, 176-191. doi:10.1111/j.1749-6632.1999.tb07825.x

Gibson, G. E., Starkov, A., Blass, J. P., Ratan, R. R., and Beal, M. F. (2010). Cause and consequence: mitochondrial dysfunction initiates and propagates neuronal dysfunction, neuronal death and behavioral abnormalities in ageassociated neurodegenerative diseases. Biochim. Biophys. Acta 1802, 122-134. doi:10.1016/j.bbadis.2009.08.010

Glass, C. K., Saijo, K., Winner, B., Marchetto, M. C., and Gage, F. H. (2010). Mechanisms underlying inflammation in neurodegeneration. Cell 140, 918-934. doi:10.1016/j.cell.2010.02.016

Gourine, A. V., Dale, N., Llaudet, E., Poputnikov, D. M., Spyer, K. M., and Gourine, V. N. (2007). Release of ATP in the central nervous system during systemic inflammation: real-time measurement in the hypothalamus of conscious rabbits. $J$. Physiol. 585(Pt 1), 305-316. doi:10.1113/jphysiol.2007.143933

Griffin, W. S., Nicoll, J. A., Grimaldi, L. M., Sheng, J. G., and Mrak, R. E. (2000). The pervasiveness of interleukin-1 in Alzheimer pathogenesis: a role for specific polymorphisms in disease risk. Exp. Gerontol. 35, 481-487. doi:10.1016/S05315565(00)00110-8

Griffin, W. S., Stanley, L. C., Ling, C., White, L., MacLeod, V., Perrot, L. J., et al. (1989). Brain interleukin 1 and S-100 immunoreactivity are elevated in Down syndrome and Alzheimer disease. Proc. Natl. Acad. Sci. U.S.A. 86, 7611-7615. doi:10.1073/pnas.86.19.7611

Han, J., Jiang, Y., Li, Z., Kravchenko, V. V., and Ulevitch, R. J. (1997). Activation of the transcription factor MEF2C by the MAP kinase p38 in inflammation. Nature 386, 296-299. doi:10.1038/386296a0

Harold, D., Abraham, R., Hollingworth, P., Sims, R., Gerrish, A., Hamshere, M. L., et al. (2009). Genome-wide association study identifies variants at CLU and PICALM associated with Alzheimer's disease. Nat. Genet. 41, 1088-1093. doi:10.1038/ng.440

Hazrati, L. N., Van Cauwenberghe, C., Brooks, P. L., Brouwers, N., Ghani, M., Sato, C., et al. (2012). Genetic association of CR1 with Alzheimer's disease: a tentative disease mechanism. Neurobiol. Aging 33, 2949.e5-2949.e12. doi:10. 1016/j.neurobiolaging.2012.07.001

Heneka, M. T., Kummer, M. P., Stutz, A., Delekate, A., Schwartz, S., Vieira-Saecker, A., et al. (2013). NLRP3 is activated in Alzheimer's disease and contributes to pathology in APP/PS1 mice. Nature 493, 674-678. doi:10.1038/nature11729

Hide, I., Tanaka, M., Inoue, A., Nakajima, K., Kohsaka, S., Inoue, K., et al. (2000). Extracellular ATP triggers tumor necrosis factor-alpha release from rat microglia. J. Neurochem. 75, 965-972. doi:10.1046/j.1471-4159.2000.0750965.x

Hiona, A., Sanz, A., Kujoth, G. C., Pamplona, R., Seo, A. Y., Hofer, T., et al. (2010). Mitochondrial DNA mutations induce mitochondrial dysfunction, apoptosis and sarcopenia in skeletal muscle of mitochondrial DNA mutator mice. PLoS ONE 5:e11468. doi:10.1371/journal.pone.0011468

Hollingworth, P., Harold, D., Sims, R., Gerrish, A., Lambert, J. C., Carrasquillo, M. M., et al. (2011). Common variants at ABCA7, MS4A6A/MS4A4E, EPHA1, CD33 and CD2AP are associated with Alzheimer's disease. Nat. Genet. 43, 429-435. doi:10.1038/ng. 803

Honea, R. A., Vidoni, E. D., Swerdlow, R. H., and Burns, J. M. (2012). Alzheimer's Disease Neuroimaging I. Maternal family history is associated with Alzheimer's disease biomarkers. J. Alzheimers Dis. 31, 659-668. doi:10.3233/JAD-2012-120676

Ishii, T., and Haga, S. (1976). Immuno-electron microscopic localization of immunoglobulins in amyloid fibrils of senile plaques. Acta Neuropathol. 36, 243-249. doi:10.1007/BF00685368

Ishii, Y., Nagasawa, K., Mayumi, T., and Niho, Y. (1990). Clinical importance of persistence of anticardiolipin antibodies in systemic lupus erythematosus. Ann. Rheum. Dis. 49, 387-390. doi:10.1136/ard.49.6.387

Ivanov, A. I., and Romanovsky, A. A. (2006). Putative dual role of ephrin-Eph receptor interactions in inflammation. IUBMB Life 58, 389-394. doi:10.1080/ 15216540600756004

Jiang, T., Yu, J. T., Zhu, X. C., and Tan, L. (2013). TREM2 in Alzheimer's disease. Mol. Neurobiol. 48, 180-185. doi:10.1007/s12035-013-8424-8

Jonsson, T., Stefansson, H., Steinberg, S., Jonsdottir, I., Jonsson, P. V., Snaedal, J., et al. (2013). Variant of TREM2 associated with the risk of Alzheimer's disease. N. Engl. J. Med. 368, 107-116. doi:10.1056/NEJMoa1211103

Julian, M. W., Shao, G., Bao, S., Knoell, D. L., Papenfuss, T. L., VanGundy, Z. C., et al. (2012). Mitochondrial transcription factor A serves as a danger signal by augmenting plasmacytoid dendritic cell responses to DNA. J. Immunol. 189, 433-443. doi:10.4049/jimmunol.1101375

Julian, M. W., Shao, G., Vangundy, Z. C., Papenfuss, T. L., and Crouser, E. D. (2013). Mitochondrial transcription factor A, an endogenous danger signal, promotes TNFalpha release via RAGE- and TLR9-responsive plasmacytoid dendritic cells. PLoS ONE 8:e72354. doi:10.1371/journal.pone.0072354

Kaczmarek, A., Vandenabeele, P., and Krysko, D. V. (2013). Necroptosis: the release of damage-associated molecular patterns and its physiological relevance. Immunity 38, 209-223. doi:10.1016/j.immuni.2013.02.003

Kish, S. J. (1997). Brain energy metabolizing enzymes in Alzheimer's disease: alphaketoglutarate dehydrogenase complex and cytochrome oxidase. Ann. N. Y. Acad. Sci. 826, 218-228. doi:10.1111/j.1749-6632.1997.tb48473.x

Kleinberger, G., Yamanishi, Y., Suarez-Calvet, M., Czirr, E., Lohmann, E., Cuyvers, E., et al. (2014). TREM2 mutations implicated in neurodegeneration impair cell surface transport and phagocytosis. Sci. Transl. Med. 6, 243 ra86.

Krysko, D. V., Agostinis, P., Krysko, O., Garg, A. D., Bachert, C., Lambrecht, B. N., et al. (2011). Emerging role of damage-associated molecular patterns derived from mitochondria in inflammation. Trends Immunol. 32, 157-164. doi:10.1016/j.it.2011.01.005

Kucher, B. M., and Neary, J. T. (2005). Bi-functional effects of ATP/P2 receptor activation on tumor necrosis factor-alpha release in lipopolysaccharidestimulated astrocytes. J. Neurochem. 92, 525-535. doi:10.1111/j.1471-4159.2004. 02885.x

Kujoth, G. C., Hiona, A., Pugh, T. D., Someya, S., Panzer, K., Wohlgemuth, S. E., et al. (2005). Mitochondrial DNA mutations, oxidative stress, and apoptosis in mammalian aging. Science 309, 481-484. doi:10.1126/science.1112125

Kurashima, Y., Amiya, T., Nochi, T., Fujisawa, K., Haraguchi, T., Iba, H., et al. (2012). Extracellular ATP mediates mast cell-dependent intestinal inflammation through P2X7 purinoceptors. Nat. Commun. 3, 1034. doi:10.1038/ncomms2023

Lambert, J. C., Heath, S., Even, G., Campion, D., Sleegers, K., Hiltunen, M., et al. (2009). Genome-wide association study identifies variants at CLU and CR1 associated with Alzheimer's disease. Nat. Genet. 41, 1094-1099. doi:10.1038/ng. 439 
Lambert, J. C., Ibrahim-Verbaas, C. A., Harold, D., Naj, A. C., Sims, R., Bellenguez, C., et al. (2013). Meta-analysis of 74,046 individuals identifies 11 new susceptibility loci for Alzheimer's disease. Nat. Genet. 45, 1452-1458. doi:10. 1038/ng.2802

Latz, E., Xiao, T. S., and Stutz, A. (2013). Activation and regulation of the inflammasomes. Nat. Rev. Immunol. 13, 397-411. doi:10.1038/nri3452

Letiembre, M., Liu, Y., Walter, S., Hao, W., Pfander, T., Wrede, A., et al. (2009). Screening of innate immune receptors in neurodegenerative diseases: a similar pattern. Neurobiol. Aging 30, 759-768. doi:10.1016/j.neurobiolaging.2007.08.018

Licastro, F., Pedrini, S., Caputo, L., Annoni, G., Davis, L. J., Ferri, C., et al. (2000). Increased plasma levels of interleukin-1, interleukin-6 and alpha-1antichymotrypsin in patients with Alzheimer's disease: peripheral inflammation or signals from the brain? J. Neuroimmunol. 103, 97-102. doi:10.1016/S01655728(99)00226-X

Lim, J. E., Kou, J., Song, M., Pattanayak, A., Jin, J., Lalonde, R., et al. (2011). MyD88 deficiency ameliorates beta-amyloidosis in an animal model of Alzheimer's disease. Am. J. Pathol. 179, 1095-1103. doi:10.1016/j.ajpath.2011.05.045

Little, J. P., Simtchouk, S., Schindler, S. M., Villanueva, E. B., Gill, N. E., Walker, D. G., et al. (2014). Mitochondrial transcription factor A (Tfam) is a pro-inflammatory extracellular signaling molecule recognized by brain microglia. Mol. Cell. Neurosci. 60, 88-96. doi:10.1016/j.mcn.2014.04.003

Liu, Y., Walter, S., Stagi, M., Cherny, D., Letiembre, M., Schulz-Schaeffer, W., et al. (2005). LPS receptor (CD14): a receptor for phagocytosis of Alzheimer's amyloid peptide. Brain 128(Pt 8), 1778-1789. doi:10.1093/brain/awh531

Long-Smith, C. M., Sullivan, A. M., and Nolan, Y. M. (2009). The influence of microglia on the pathogenesis of Parkinson's disease. Prog. Neurobiol. 89, 277-287. doi:10.1016/j.pneurobio.2009.08.001

Lue, L. F., Walker, D. G., Brachova, L., Beach, T. G., Rogers, J., Schmidt, A. M., et al. (2001). Involvement of microglial receptor for advanced glycation endproducts (RAGE) in Alzheimer's disease: identification of a cellular activation mechanism. Exp. Neurol. 171, 29-45. doi:10.1006/exnr.2001.7732

Mamula, M. J., Jemmerson, R., and Hardin, J. A. (1990). The specificity of human anti-cytochrome $\mathrm{c}$ autoantibodies that arise in autoimmune disease. J. Immunol. 144, 1835-1840.

Manczak, M., Park, B. S., Jung, Y., and Reddy, P. H. (2004). Differential expression of oxidative phosphorylation genes in patients with Alzheimer's disease: implications for early mitochondrial dysfunction and oxidative damage. Neuromolecular Med. 5, 147-162. doi:10.1385/NMM:5:2:147

Marano, C. M., Workman, C. I., Kramer, E., Hermann, C. R., Ma, Y., Dhawan, V., et al. (2013). Longitudinal studies of cerebral glucose metabolism in latelife depression and normal aging. Int. J. Geriatr. Psychiatry 28, 417-423. doi:10.1002/gps.3840

Marcus, D. L., Strafaci, J. A., Miller, D. C., Masia, S., Thomas, C. G., Rosman, J., et al. (1998). Quantitative neuronal c-fos and c-jun expression in Alzheimer's disease. Neurobiol. Aging 19, 393-400. doi:10.1016/S0197-4580(98)00077-3

Mathew, A., Lindsley, T. A., Sheridan, A., Bhoiwala, D. L., Hushmendy, S. F., Yager, E. J., et al. (2012). Degraded mitochondrial DNA is a newly identified subtype of the damage associated molecular pattern (DAMP) family and possible trigger of neurodegeneration. J. Alzheimers Dis. 30, 617-627. doi:10.3233/JAD-2012-120145

Maurer, I., Zierz, S., and Möller, H. J. (2000). A selective defect of cytochrome c oxidase is present in brain of Alzheimer disease patients. Neurobiol. Aging 21, 455-462. doi:10.1016/S0197-4580(00)00112-3

Mazarati, A., Maroso, M., Iori, V., Vezzani, A., and Carli, M. (2011). High-mobility group box-1 impairs memory in mice through both toll-like receptor 4 and receptor for advanced glycation end products. Exp. Neurol. 232, 143-148. doi:10.1016/j.expneurol.2011.08.012

McGeer, P. L., and McGeer, E. G. (2001). Polymorphisms in inflammatory genes and the risk of Alzheimer disease. Arch. Neurol. 58, 1790-1792. doi:10.1001/archneur. 58.11.1790

McGeer, P. L., and McGeer, E. G. (2008). Glial reactions in Parkinson's disease. Mov. Disord. 23, 474-483. doi:10.1002/mds.21751

Mecocci, P., MacGarvey, U., and Beal, M. F. (1994). Oxidative damage to mitochondrial DNA is increased in Alzheimer's disease. Ann. Neurol. 36, 747-751. doi:10.1002/ana.410360510

Mehta, P. D., Pirttila, T., Mehta, S. P., Sersen, E. A., Aisen, P. S., and Wisniewski, H. M. (2000). Plasma and cerebrospinal fluid levels of amyloid beta proteins 1-40 and 1-42 in Alzheimer disease. Arch. Neurol. 57, 100-105. doi:10.1001/archneur. 57.1 .100
Mosconi, L., Brys, M., Switalski, R., Mistur, R., Glodzik, L., Pirraglia, E., et al. (2007). Maternal family history of Alzheimer's disease predisposes to reduced brain glucose metabolism. Proc. Natl. Acad. Sci. U.S.A. 104, 19067-19072. doi:10.1073/pnas.0705036104

Nakahira, K., Haspel, J. A., Rathinam, V. A., Lee, S. J., Dolinay, T., Lam, H. C., et al. (2011). Autophagy proteins regulate innate immune responses by inhibiting the release of mitochondrial DNA mediated by the NALP3 inflammasome. Nat. Immunol. 12, 222-230. doi:10.1038/ni.1980

Nakahira, K., Kyung, S. Y., Rogers, A. J., Gazourian, L., Youn, S., Massaro, A. F., et al. (2013). Circulating mitochondrial DNA in patients in the ICU as a marker of mortality: derivation and validation. PLoS Med. 10:e1001577. doi:10.1371/journal.pmed.1001577

Navarro, A., and Boveris, A. (2004). Rat brain and liver mitochondria develop oxidative stress and lose enzymatic activities on aging. Am. J. Physiol. Regul. Integr. Comp. Physiol. 287, R1244-R1249. doi:10.1152/ajpregu.00226.2004

Navarro, A., and Boveris, A. (2007). The mitochondrial energy transduction system and the aging process. Am. J. Physiol. Cell Physiol. 292, C670-C686. doi:10.1152/ajpcell.00213.2006

Navarro, A., and Boveris, A. (2010). Brain mitochondrial dysfunction in aging, neurodegeneration, and Parkinson's disease. Front. Aging Neurosci. 2:34. doi:10.3389/ fnagi.2010.00034

Oka, T., Hikoso, S., Yamaguchi, O., Taneike, M., Takeda, T., Tamai, T., et al. (2012). Mitochondrial DNA that escapes from autophagy causes inflammation and heart failure. Nature 485, 251-255. doi:10.1038/nature10992

Onyango, I. G., Bennett, J. P. Jr., and Tuttle, J. B. (2005). Endogenous oxidative stress in sporadic Alzheimer's disease neuronal cybrids reduces viability by increasing apoptosis through pro-death signaling pathways and is mimicked by oxidant exposure of control cybrids. Neurobiol. Dis. 19, 312-322. doi:10.1016/j.nbd.2005.01.026

Onyango, I. G., and Khan, S. M. (2006). Oxidative stress, mitochondrial dysfunction, and stress signaling in Alzheimer's disease. Curr. Alzheimer Res. 3, 339-349. doi: $10.2174 / 156720506778249489$

Pan, Z. K., Chen, L. Y., Cochrane, C. G., and Zuraw, B. L. (2000). fMet-Leu-Phe stimulates proinflammatory cytokine gene expression in human peripheral blood monocytes: the role of phosphatidylinositol 3-kinase. J. Immunol. 164, 404-411. doi:10.4049/jimmunol.164.1.404

Papaliagkas, V. T., Anogianakis, G., Tsolaki, M. N., Koliakos, G., and Kimiskidis, V. K. (2009). Prediction of conversion from mild cognitive impairment to Alzheimer's disease by CSF cytochrome c levels and N200 latency. Curr. Alzheimer Res. 6, 279-284. doi:10.2174/156720509788486626

Parker, W. D. Jr., Filley, C. M., and Parks, J. K. (1990). Cytochrome oxidase deficiency in Alzheimer's disease. Neurology 40, 1302-1303. doi:10.1212/WNL.40.8.1302

Piccini, A., Carta, S., Tassi, S., Lasiglie, D., Fossati, G., and Rubartelli, A. (2008). ATP is released by monocytes stimulated with pathogen-sensing receptor ligands and induces IL-1beta and IL-18 secretion in an autocrine way. Proc. Natl. Acad. Sci. U.S.A. 105, 8067-8072. doi:10.1073/pnas.0709684105

Podlesniy, P., Figueiro-Silva, J., Llado, A., Antonell, A., Sanchez-Valle, R., Alcolea, D., et al. (2013). Low cerebrospinal fluid concentration of mitochondrial DNA in preclinical Alzheimer disease. Ann. Neurol. 74, 655-668. doi:10.1002/ana.23955

Porto, A., Palumbo, R., Pieroni, M., Aprigliano, G., Chiesa, R., Sanvito, F., et al. (2006). Smooth muscle cells in human atherosclerotic plaques secrete and proliferate in response to high mobility group box 1 protein. FASEB J. 20, 2565-2566. doi:10.1096/fj.06-5867fje

Pullerits, R., Bokarewa, M., Jonsson, I. M., Verdrengh, M., and Tarkowski, A. (2005). Extracellular cytochrome c, a mitochondrial apoptosis-related protein, induces arthritis. Rheumatology 44, 32-39. doi:10.1093/rheumatology/keh406

Raoof, M., Zhang, Q., Itagaki, K., and Hauser, C. J. (2010). Mitochondrial peptides are potent immune activators that activate human neutrophils via FPR-1. J. Trauma 68, 1328-1332; discussion 32-4. doi:10.1097/TA.0b013e3181dcd28d

Rich, J. B., Rasmusson, D. X., Folstein, M. F., Carson, K. A., Kawas, C., and Brandt, J. (1995). Nonsteroidal anti-inflammatory drugs in Alzheimer's disease. Neurology 45, 51-55. doi:10.1212/WNL.45.1.51

Riteau, N., Gasse, P., Fauconnier, L., Gombault, A., Couegnat, M., Fick, L., et al. (2010). Extracellular ATP is a danger signal activating P2X7 receptor in lung inflammation and fibrosis. Am. J. Respir. Crit. Care Med. 182, 774-783. doi:10.1164/rccm.201003-0359OC

Ross, J. M., Stewart, J. B., Hagstrom, E., Brene, S., Mourier, A., Coppotelli, G., et al. (2013). Germline mitochondrial DNA mutations aggravate ageing and can impair brain development. Nature 501, 412-415. doi:10.1038/nature12474 
Scaffidi, P., Misteli, T., and Bianchi, M. E. (2002). Release of chromatin protein HMGB1 by necrotic cells triggers inflammation. Nature 418, 191-195. doi:10.1038/nature00858

Shaftel, S. S., Griffin, W. S., and O'Banion, M. K. (2008). The role of interleukin-1 in neuroinflammation and Alzheimer disease: an evolving perspective. J. Neuroinflammation 5, 7. doi:10.1186/1742-2094-5-7

Shaikh, S. B., and Nicholson, L. F. (2009). Effects of chronic low dose rotenone treatment on human microglial cells. Mol. Neurodegener. 4, 55. doi:10.1186/17501326-4-55

Sheehan, J. P., Swerdlow, R. H., Miller, S. W., Davis, R. E., Parks, J. K., Parker, W. D., et al. (1997). Calcium homeostasis and reactive oxygen species production in cells transformed by mitochondria from individuals with sporadic Alzheimer's disease. J. Neurosci. 17, 4612-4622.

Sherer, T. B., Betarbet, R., Kim, J. H., and Greenamyre, J. T. (2003). Selective microglial activation in the rat rotenone model of Parkinson's disease. Neurosci. Lett. 341, 87-90. doi:10.1016/S0304-3940(03)00172-1

Shigenaga, M. K., Hagen, T. M., and Ames, B. N. (1994). Oxidative damage and mitochondrial decay in aging. Proc. Natl. Acad. Sci. U.S.A. 91, 10771-10778. doi:10.1073/pnas.91.23.10771

Silva, D. F., Santana, I., Esteves, A. R., Baldeiras, I., Arduino, D. M., Oliveira, C. R., et al. (2013). Prodromal metabolic phenotype in MCI cybrids: implications for Alzheimer's disease. Curr. Alzheimer Res. 10, 180-190. doi:10.2174/ 1567205011310020008

Silva, D. F., Selfridge, J. E., Lu, J. E. L., Cardoso, S. M., and Swerdlow, R. H. (2012). Mitochondrial abnormalities in Alzheimer's disease: possible targets for therapeutic intervention. Adv. Pharmacol. 64, 83-126. doi:10.1016/B978-0-12394816-8.00003-9

Singh, V. K., and Guthikonda, P. (1997). Circulating cytokines in Alzheimer's disease. J. Psychiatr. Res. 31, 657-660. doi:10.1016/S0022-3956(97)00023-X

Singh-Manoux, A., Dugravot, A., Brunner, E., Kumari, M., Shipley, M., Elbaz, A., et al. (2014). Interleukin-6 and C-reactive protein as predictors of cognitive decline in late midlife. Neurology 83, 486-493. doi:10.1212/WNL.0000000000000665

Sodhi, A., and Biswas, S. K. (2002). fMLP-induced in vitro nitric oxide production and its regulation in murine peritoneal macrophages. J. Leukoc. Biol. 71, 262-270.

Stumbo, A. C., Cortez, E., Rodrigues, C. A., Henriques, M., Porto, L. C., Barbosa, H. S., et al. (2008). Mitochondrial localization of non-histone protein HMGB1 during human endothelial cell-Toxoplasma gondii infection. Cell Biol. Int. 32, 235-238. doi:10.1016/j.cellbi.2007.08.031

Sundelof, J., Kilander, L., Helmersson, J., Larsson, A., Ronnemaa, E., DegermanGunnarsson, M., et al. (2009). Systemic inflammation and the risk of Alzheimer's disease and dementia: a prospective population-based study. J. Alzheimers Dis. 18, 79-87. doi:10.3233/JAD-2009-1126

Suzuki, T., Hide, I., Ido, K., Kohsaka, S., Inoue, K., and Nakata, Y. (2004). Production and release of neuroprotective tumor necrosis factor by $\mathrm{P} 2 \mathrm{X} 7$ receptor-activated microglia. J. Neurosci. 24, 1-7. doi:10.1523/JNEUROSCI.3792-03.2004

Swardfager, W., Lanctot, K., Rothenburg, L., Wong, A., Cappell, J., and Herrmann, N. (2010). A meta-analysis of cytokines in Alzheimer's disease. Biol. Psychiatry 68, 930-941. doi:10.1016/j.biopsych.2010.06.012

Swerdlow, R. H. (2002). Mitochondrial DNA - related mitochondrial dysfunction in neurodegenerative diseases. Arch. Pathol. Lab. Med. 126, 271-280.

Swerdlow, R. H. (2011). Brain aging, Alzheimer's disease, and mitochondria. Biochim. Biophys. Acta 1812, 1630-1639. doi:10.1016/j.bbadis.2011.08.012

Swerdlow, R. H. (2012). Mitochondria and cell bioenergetics: increasingly recognized components and a possible etiologic cause of Alzheimer's disease. Antioxid. Redox Signal. 16, 1434-1455. doi:10.1089/ars.2011.4149

Swerdlow, R. H. (2014). Bioenergetic medicine. Br. J. Pharmacol. 171, 1854-1869. doi:10.1111/bph.12394

Swerdlow, R. H., and Khan, S. M. (2004). A "mitochondrial cascade hypothesis" for sporadic Alzheimer's disease. Med. Hypotheses 63, 8-20. doi:10.1016/j.mehy. 2003.12.045

Swerdlow, R. H., and Kish, S. J. (2002). Mitochondria in Alzheimer's disease. Int. Rev. Neurobiol. 53, 341-385. doi:10.1016/S0074-7742(02)53013-0

Swerdlow, R. H., Parks, J. K., Cassarino, D. S., Maguire, D. J., Maguire, R. S., Bennett, J. P. Jr., et al. (1997). Cybrids in Alzheimer's disease: a cellular model of the disease? Neurology 49, 918-925. doi:10.1212/WNL.49.4.918

Tan, Z. S., Beiser, A. S., Vasan, R. S., Roubenoff, R., Dinarello, C. A., Harris, T. B., et al. (2007). Inflammatory markers and the risk of Alzheimer disease: the Framingham study. Neurology 68, 1902-1908. doi:10.1212/01.wnl.0000263217. 36439.da
Tang, D., Kang, R., Livesey, K. M., Cheh, C. W., Farkas, A., Loughran, P., et al. (2010). Endogenous HMGB1 regulates autophagy. J. Cell Biol. 190, 881-892. doi:10.1083/jcb.200911078

Trifunovic, A., Wredenberg, A., Falkenberg, M., Spelbrink, J. N., Rovio, A. T., Bruder, C. E., et al. (2004). Premature ageing in mice expressing defective mitochondrial DNA polymerase. Nature 429, 417-423. doi:10.1038/nature02517

van Golen, R. F., Reiniers, M. J., Olthof, P. B., van Gulik, T. M., and Heger, M. (2013). Sterile inflammation in hepatic ischemia/reperfusion injury: present concepts and potential therapeutics. J. Gastroenterol. Hepatol. 28, 394-400. doi:10.1111/jgh.12072

Vazquez-Higuera, J. L., Rodriguez-Rodriguez, E., Sanchez-Juan, P., Mateo, I., Pozueta, A., Martinez-Garcia, A., et al. (2010). Caspase-1 genetic variation is not associated with Alzheimer's disease risk. BMC Med. Genet. 11:32. doi:10.1186/ 1471-2350-11-32

Verdier, Y., Zarandi, M., and Penke, B. (2004). Amyloid beta-peptide interactions with neuronal and glial cell plasma membrane: binding sites and implications for Alzheimer's disease. J. Pept. Sci. 10, 229-248. doi:10.1002/psc.573

Versijpt, J. J., Dumont, F., Van Laere, K. J., Decoo, D., Santens, P., Audenaert, K., et al. (2003). Assessment of neuroinflammation and microglial activation in Alzheimer's disease with radiolabelled PK11195 and single photon emission computed tomography. A pilot study. Eur. Neurol. 50, 39-47. doi:10.1159/ 000070857

Walko, T. D. III, Bola, R. A., Hong, J. D., Au, A. K., Bell, M. J., Kochanek, P. M., et al. (2014). Cerebrospinal fluid mitochondrial DNA: a novel DAMP in pediatric traumatic brain injury. Shock 41, 499-503. doi:10.1097/SHK.0000000000000160

Wallin, A. K., Blennow, K., Andreasen, N., and Minthon, L. (2006). CSF biomarkers for Alzheimer's Disease: levels of beta-amyloid, tau, phosphorylated tau relate to clinical symptoms and survival. Dement. Geriatr. Cogn. Disord. 21, 131-138. doi:10.1159/000090631

Walter, S., Letiembre, M., Liu, Y., Heine, H., Penke, B., Hao, W., et al. (2007). Role of the toll-like receptor 4 in neuroinflammation in Alzheimer's disease. Cell. Physiol. Biochem. 20, 947-956. doi:10.1159/000110455

Wan, M., Hua, X., Su, J., Thiagarajan, D., Frostegard, A. G., Haeggstrom, J. Z., et al. (2014). Oxidized but not native cardiolipin has pro-inflammatory effects, which are inhibited by Annexin A5. Atherosclerosis 235, 592-598. doi:10.1016/j. atherosclerosis.2014.05.913

Wang, L. Z., Yu, J. T., Miao, D., Wu, Z. C., Zong, Y., Wen, C. Q., et al. (2011). Genetic association of TLR4/11367 polymorphism with late-onset Alzheimer's disease in a Han Chinese population. Brain Res. 1381, 202-207. doi:10.1016/j.brainres. 2011.01 .007

Wang, Y. L., Tan, M. S., Yu, J. T., Zhang, W., Hu, N., Wang, H. F., et al. (2013). Toll-like receptor 9 promoter polymorphism is associated with decreased risk of Alzheimer's disease in Han Chinese. J. Neuroinflammation 10, 101. doi:10.1186/1742-2094-10-101

Wilkins, H. M., Carl, S. M., and Swerdlow, R. H. (2014). Cytoplasmic hybrid (cybrid) cell lines as a practical model for mitochondriopathies. Redox Biol. 2, 619-631. doi:10.1016/j.redox.2014.03.006

Xie, J., Mendez, J. D., Mendez-Valenzuela, V., and Aguilar-Hernandez, M. M. (2013). Cellular signalling of the receptor for advanced glycation end products (RAGE). Cell. Signal. 25, 2185-2197. doi:10.1016/j.cellsig.2013.06.013

Yu, J. T., Mou, S. M., Wang, L. Z., Mao, C. X., and Tan, L. (2011a). Tolllike receptor $2-196$ to -174 del polymorphism influences the susceptibility of Han Chinese people to Alzheimer's disease. J. Neuroinflammation 8, 136. doi:10.1186/1742-2094-8-136

Yu, J. T., Sun, Y. P., Ou, J. R., Cui, W. Z., Zhang, W., and Tan, L. (2011b). No association of toll-like receptor 2 polymorphisms with Alzheimer's disease in Han Chinese. Neurobiol. Aging 32, 1924.e1-3. doi:10.1016/j.neurobiolaging.2011.03.023

Zhang, J. Z., Liu, Z., Liu, J., Ren, J. X., and Sun, T. S. (2014). Mitochondrial DNA induces inflammation and increases TLR9/NF-kappaB expression in lung tissue. Int. J. Mol. Med. 33, 817-824. doi:10.3892/ijmm.2014.1650

Zhang, Q., Raoof, M., Chen, Y., Sumi, Y., Sursal, T., Junger, W., et al. (2010). Circulating mitochondrial DAMPs cause inflammatory responses to injury. Nature 464, 104-107. doi:10.1038/nature08780

Zhang, W., Wang, L. Z., Yu, J. T., Chi, Z. F., and Tan, L. (2012). Increased expressions of TLR2 and TLR4 on peripheral blood mononuclear cells from patients with Alzheimer's disease. J. Neurol. Sci. 315, 67-71. doi:10.1016/j.jns.2011.11.032

Zhou, R., Yazdi, A. S., Menu, P., and Tschopp, J. (2011). A role for mitochondria in NLRP3 inflammasome activation. Nature 469, 221-225. doi:10.1038/ nature 09663 
Zitvogel, L., Kepp, O., and Kroemer, G. (2010). Decoding cell death signals in inflammation and immunity. Cell 140, 798-804. doi:10.1016/j.cell.2010.02.015

Conflict of Interest Statement: The authors declare that the research was conducted in the absence of any commercial or financial relationships that could be construed as a potential conflict of interest.

Received: 10 September 2014; accepted: 23 October 2014; published online: 10 November 2014
Citation: Wilkins HM, Carl SM, Greenlief ACS, Festoff BW and Swerdlow RH (2014) Bioenergetic dysfunction and inflammation in Alzheimer's disease: a possible connection. Front. Aging Neurosci. 6:311. doi: 10.3389/fnagi.2014.00311 This article was submitted to the journal Frontiers in Aging Neuroscience.

Copyright (C) 2014 Wilkins, Carl, Greenlief, Festoff and Swerdlow. This is an openaccess article distributed under the terms of the Creative Commons Attribution License (CC BY). The use, distribution or reproduction in other forums is permitted, provided the original author(s) or licensor are credited and that the original publication in this journal is cited, in accordance with accepted academic practice. No use, distribution or reproduction is permitted which does not comply with these terms. 